\title{
Development of Metal-impregnated Single Walled Carbon Nanotubes for Toxic Gas Contaminant Control in Advanced Life Support Systems
}

\author{
Martin Cinke, Jing Li, Bin Chen \\ Eloret Corporation, NASA Ames Research Center, Moffett Field, CA 94035-1000 \\ Kanapathipillai Wignarajah, Suresh Pisharody \\ Lockheed Martin Company, NASA Ames Research Center, Moffett Field, CA 94035-1000 \\ John Fisher, Lance Delzeit, Meyya Meyyappan, Harry Partridge \\ NASA Ames Research Center. Moffett Field, CA 94035-100 \\ Kimberlee Clark \\ Foothill-Deanza College Intern, NASA Ames Research Center, Moffett Field, CA 94035-1000
}

Copyright $\odot 2003$ SAE International

\begin{abstract}
The success of physico-chemical waste processing and resource recovery technologies for life support application depends partly on the ability of gas clean-up systems to efficiently remove trace contaminants generated during the process with minimal use of expendables. Highly purified metal-impregnated carbon nanotubes promise superior performance over conventional approaches to gas clean-up due to their ability to direct the selective uptake gaseous species based both on the nanotube's controlled pore size, high surface area, and ordered chemical structure that allows functionalization and on the nanotube's effectiveness as a catalyst support material for toxic contaminants removal. We present results on the purification of single walled carbon nanotubes (SWCNT) and efforts at metal impregnation of the SWCNT's.
\end{abstract}

\section{INTRODUCTION}

\section{CARBON MATERIALS ON SPACE HABITATS}

Carbon materials have long been used in environmental remediation and waste treatment for removal of toxic contaminants in both gaseous and liquid environments. On Space Station Mir, the air revitalization system included:

(i) an expendable charcoal canister (weighing $6 \mathrm{Kg}$ and having $1.3 \mathrm{Kg}$ activated charcoal), (ii) two regenerable canisters (weighing $16 \mathrm{Kg}$ each and having $7.4 \mathrm{Kg}$ activated carbon each) and which are regenerated every 20 days,

(iii) an ambient temperature catalyst containing $0.5 \mathrm{Kg}$ of a precious metal catalyst, and

Activated carbon has been extensively used due to a number of factors that include low-cost production and high surface area. However, some of the drawbacks to activated carbons are 1) non molecular defined chemical structure, 2) lack of specificity due to broad pore size distribution, 3) small pore volume and the associated low uptake weight for volatile gases, including $\mathrm{NO}_{\mathrm{x}}$ compounds.

\section{CARBON NANO TUBES (CNT) - AN ALTERNATIVE}

A carbon nanotube can be thought of as a graphene sheet that is rolled into a seamless cylinder (figure 1), where the outside diameter can be $\sim 0.4 \mathrm{~nm}$ for the smallest SWCNT to over $10 \mathrm{~nm}$ for the largest diameter tubes. Their length depends on the production method, and can vary from $100 \mathrm{~nm}$ to $10 \mathrm{~cm}$.

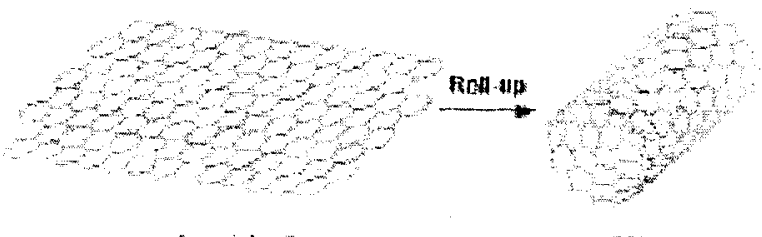

grophane xhack

swar

Figure 1 - Schematic showing rolling-up of a graphene sheet to produce a Single walled Nanotube 
Some additional unique properties that carbon nanotubes possess are an unusually high strength to weight ratio ( 3 times that of steel), electrical conductivity (metallic/semi-conducting) depending on the helicity (chiral twist of carbon atoms in the tube), and selective adsorptive properties. SWCNTs possess higher surface area than activated carbon (theoretical value is $3200 \mathrm{~m}^{2} / \mathrm{g}$ which is 2-3 times higher than activated carbon) [1]. Theoretical predictions state that with proper control of tube spacing and tube diameter, Brunauer-EmmettTeller (BET) surface areas approaching $3200 \mathrm{~m}^{2} / \mathrm{g}$ are possible for the bulk material (opened tubes), including a significant contribution from the interior pores (endohedral surface) and channels approaching 1500 $\mathrm{m}^{2} / \mathrm{g}$.

Nanotubes can be produced with unique pore properties that can impart high selectivity through the use of the inner cavity of the nanotubes, which can serve as a size selective uptake site for small gas molecules. Since carbon nanotubes are molecularly well defined, different strategies for their preparation and modification, such as chemical functionalization, can be explored to make the tube material more or less selective for gaseous uptake.

Carbon nanotubes have large pore volume thus enabling a faster process for adsorption, conversion, and separation because the quantity of uptake substances per unit time is greater.

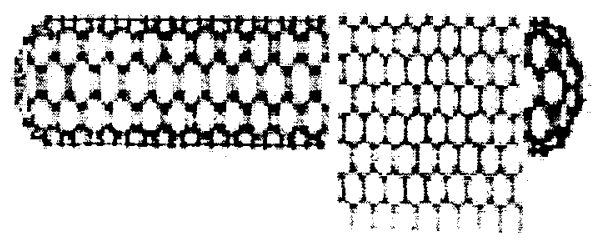

Figure 2 - Schematic of a single walled carbon nanotubes. Note the closed walls, which may be opened by oxidation.

\section{SINGLE WALLED CARBON NANOTUBES (SWCNT) \& THE HIGH PRESSURE CO DISPROPORTIONATION (HIPCO) PROCESS}

The SWCNT's used are produced in a gas-phase reaction by mixing carbon monoxide with iron pentacarbonyl (FeCO5) and heating to a high temperature. The raw HiPco produced contains between $20-30 \%$ iron[2]. This iron content must be substantially lowered to develop metal impregnated catalyst. In addition, it is important to open the pores. Efforts at purification have resulted in reducing the iron content to between $2-6 \%$ wt $\%[3,4]$. Using a procedure described by Nikolaev et al [5], Du et al [3] lowered the Fe content to $3.5 \%$, but their procedure resulted in a reduction of percentage of open pores as estimated Ar adsorption isotherms. Yudasaka et al [4] showed that high vacuum treatment for $5 \mathrm{~h}$ at $2000 \mathrm{C}$ lowered the Fe content to $2 \%$ while increasing the diameter of the SWCNT substantially. However, no attempt was made to explain the mechanism of diameter swelling. We have obtained results which show BET surface area of $1586 \mathrm{~m}^{2} / \mathrm{g}$ and iron impurity level of $<0.4 \%$ that are the highest values reported so far in the literature. We describe below an experimental protocol that we have developed to purify SWCNT.

\section{EXPERIMENTAL PROTOCOL}

EXPERIMENTAL WORK - HiPCO SWCNT
PURIFICATION

Step 1: A solvent mixture of $200 \mathrm{ml} \mathrm{DMF} \mathrm{(Aldrich,} \mathrm{99.9 \% )}$ and 100 I EDA (Aldrich, 99+\%) was used to suspend 100 mg raw HiPco SWNTs and this solution was stirred for 18 $\mathrm{h}$ followed by a $6.5 \mathrm{~h}$ sonication. The solution was then centrifuged and the solvent mixture was decanted. The precipitates were centrifuged and decanted twice with methanol as the washing solvent. The entire procedure was repeated once more. The amine and amide groups in these solvents can interact with the $\Pi$-electrons on the surface of the carbon nanotubes. Therefore, this procedure helps to loosen the nanotube bundles.

Step 2: Next, the DMF/EDA-treated SWNTs were suspended in $250 \mathrm{ml}$ of $37 \% \mathrm{HCl}$ (Aldrich) and sonicated for $15 \mathrm{~min}$ to dissolvethe nanotubes. The stirred solution was heated to $45^{\circ} \mathrm{C}$ for $2 \mathrm{~h}$. The solution was then diluted with double distilled water and cooled to room temperature because the centrifuge tubes cannot tolerate a high concentration of acid. The solution was centrifuged and decanted four times with double distilled water. The SWNTs were dried in air and placed in a quartz boat located at the center of a quartz tube connected to a water bubbler. A stream of wet air was fed into the quartz tube with the tube maintained at $225^{\circ} \mathrm{C}$ for $18 \mathrm{~h}$ and then the SWNTs were cooled to room temperature. The $\mathrm{HCl}$ treatment removes the metals and the wet air oxidation removes the amorphous carbon. This aspect of the purification procedure (i.e., the entire step 2) was repeated three more times, but with the wet air oxidation part modified slightly each time $\left(325^{\circ} \mathrm{C}\right.$ for $1.5 \mathrm{~h} ; 425^{\circ} \mathrm{C}$ for $1 \mathrm{~h}$; skipping the step, respectively). High resolution transmission electron microscopy (HRTEM) was used at various stages of the purification process to keep track of the quality of the SWNTs. The samples were also analyzed using Raman spectroscopy as described in [6]. Thermogravimetric analysis (TGA) (Perkin-Elmer TGA Pyris 1) was performed to determine the impurities, and decomposition temperature and rate. The sample was loaded in a platinum pan for weight loss measurement. The sample was burned with a ramping rate of $25^{\circ} \mathrm{C} / \mathrm{min}$ in the temperature range $50-1025^{\circ} \mathrm{C}$. Ambient air with $20 \mathrm{ml} / \mathrm{min}$ was used as carrier gas for characterizing the metal impurities. The nanopore structures were determined by adsorption of $N_{2}$ at $77 \mathrm{~K}$ using Micromeritics ASAP 2010 surface analyzer. The sample 
was loaded in a quartz tube evacuated to 10-6 Torr and cooled with liquid nitrogen to $77 \mathrm{~K} . \mathrm{N}_{2}$ gas $(99.9995 \%)$ was incrementally released into the quartz tube for adsorption measurements at different relative vapor pressures. Calculation of surface area, pore size distribution, and pore volumes was done from this characterization as outlined in [7].

\section{RESULTS AND DISCUSSION}

\section{TRANSMISSION MICROSCOPY AND RAMAN SPECTROSCOPY STUDIES}

Figure 3 shows HRTEM images and Raman spectroscopy results for raw HiPco and the two-step purified samples. TEM images show particles of $\mathrm{Fe}$ or carbon-coated $\mathrm{Fe}$ in the raw material while these are not seen in the purified sample. Raman spectra in the high frequency region show tangential mode $D$ band at 1335 $\mathrm{cm}-1$ as well as characteristic narrow $\mathrm{G}$ band around 1585 $\mathrm{cm}-1$. The $\mathrm{D}$ band structure may be due to the amorphous carbon introduced during growth as well as nanotubes with open caps or wall defects. The intensity ratio IG/ID increases slightly, after the two-step purification process, due to the removal of amorphous carbon and opening of the gaps. The curve fitting results indicate an increase in the $1547 \mathrm{~cm}-1$ component, commonly believed as the contribution from nanotubes of smaller chiral angles [8]. It is possible that some of the SWNTs undergo preferential reconstruction as an

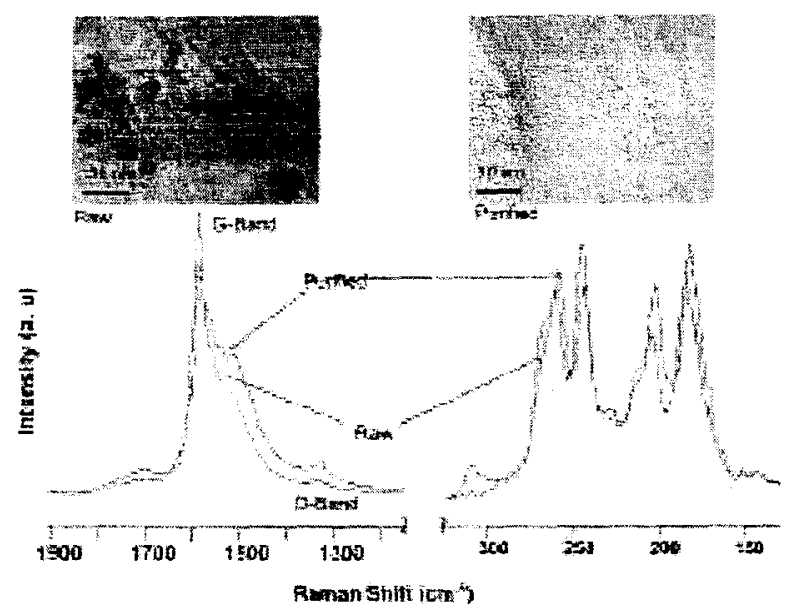

annealing process. There is no indication that the purification steps create any new defects. results (514 $\mathrm{nm}$ excitation) for raw and purified HiPco SWCNT'S
The diameter distribution estimated from the radical breathing modes (RBM) ranges from 0.93 to 1.35 $\mathrm{nm}$. The peaks corresponding to diameters of $0.94,1.01$, 1.10 and $1.16,1.22,1.35$ are seen. $A$ change in relative

Intensity for various peaks in the RBM region has been observed (both 514 and $782 \mathrm{~nm}$ excitation) indicating the ratio of small diameter nanotubes has increased after purification relative to larger diameter tubes. Such a change has been reported previously [10 and 18]. Another interesting observation is that the spectra, both in tangential and RBM regions, are blue-shifted by about $10 \mathrm{~cm}-1$ after the purification. This may be related to a decrease in internanotube interaction after the bundles are dispersed by the DMF/EDA treatment.

\section{THERMOGRAVIMETRIC ANALYSIS RESULTS}

The TGA results (Figure 4) indicate a 22 wt\% Fe content in the raw HiPco material which dropped to $0.4 \%$ after the two-step purification process. The early weight gain in the raw material is due to conversion to metal oxides. The metal impurities in the raw material lower the decomposition temperature and increase the decomposition rate. The purified material with very little metal is thermally more stable towards oxidative destruction than the raw SWNTs. Experiments also show that longer sonication periods resulted in lowering the decomposition temperature and raising the rate as expected due to the resulting shorter fragments of nanotubes.

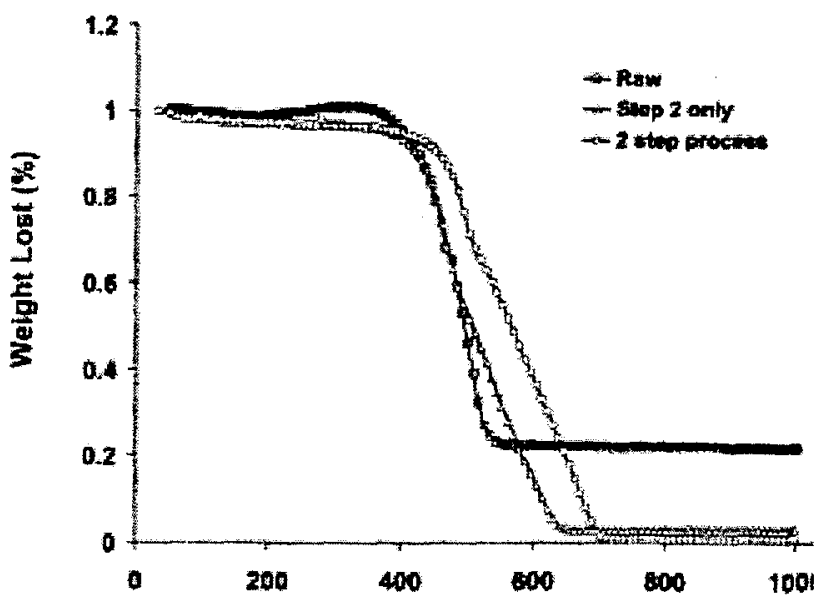

Temperature ( $\left.{ }^{\circ} \mathrm{C}\right)$

Figure 4 - Thermogravimetric analysis of purified SWCNT 


\section{$\mathrm{N}_{2}$ ADSORPTION ISOTHERMS}

$\mathrm{N}_{2}$ adsorption isotherms for the raw HiPco and the twostep purified HiPco are shown in Figure 5 . For comparison, an isotherm for a sample that was subjected only to Step 2 ( $\mathrm{HCl}$ treatment and wet oxidation) is also shown; step 2 alone is similar to the procedure in [2]. All isotherms are clearly of Type IV showing a hysterisis loop at high values of $P / P_{0}[7]$. In the intermediate pressures, the uptake of $N_{2}$ gradually increases with $P / P_{0}$. The adsorptive capacity improves significantly as expected upon purification. At $P / P_{0} 0.2$ for example, the volume adsorbed increases from $161 \mathrm{~cm}^{3} / \mathrm{g}$ STP for the raw material to $441 \mathrm{~cm}^{3} / \mathrm{g}$ STP for the completely purified sample. The 2.75-fold increase in capacity matches the increase in BET surface area discussed below. It is also evident that a substantial fraction of this improved capacity can be attributed to the debundling effects of the DMF/EDA treatment. The peak capacity at $P / P_{0}$ reaches $1000 \mathrm{~cm}^{3} / \mathrm{g}$ STP $(=1250 \mathrm{mg} / \mathrm{g})$ for the purified sample.

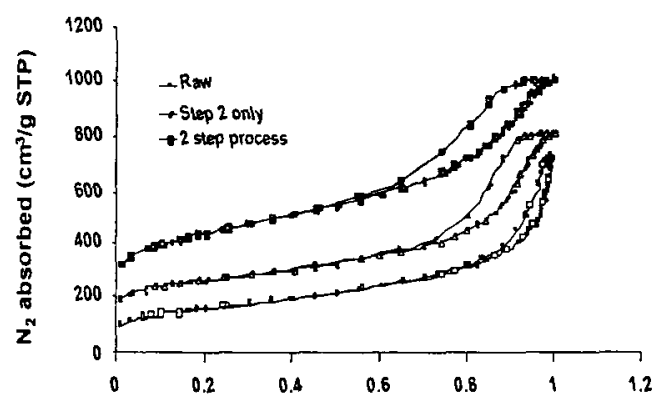

Relative Pressure (PIPo)

Figure 5. N2 Adsorption isotherms (77.6K) for raw and 2step purified samples of SWCNT's. For comparison a data from a sample treated only by step 2 is included.

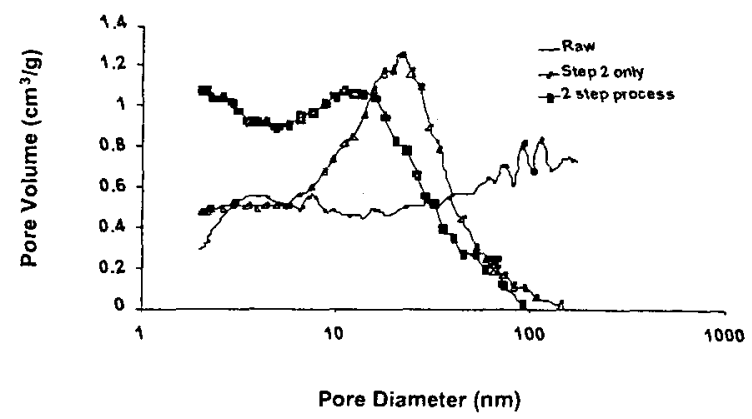

Figure 6; Pore distribution in raw and purified SWCNT's

The pore distribution data corresponding to the $N_{2}$ adsorption isotherms in figure 6 . The computed pore structure properties are listed in table 1 . The total bet surface area of raw HiPco is $577 \mathrm{~m}^{2} / \mathrm{g}$ which compares with a value of $524 \mathrm{~m}^{2} / \mathrm{g}$ for HiPco material previously reported by Yang et al. [9].any minor differences in the raw material properties between our data and those of 3] and [9] may be attributed to batch-to-batch variations of a process that is constantly undergoing improvements. Remarkably the total surface area of our completely purified sample is $1587 \mathrm{~m}^{2} / \mathrm{g}$ which is nearly twice that of the previous best values for HiPco or other SWNT's (861 $\mathrm{m}^{2} / \mathrm{g}$ in [9]). If the DMF/EDA treatment is skipped and only the acid treatment/wet oxidation is performed, we only see a total area of $968 \mathrm{~m}^{2} / \mathrm{g}$. It is clear that the debundling process by the DMF/EDA treatment is effective in increasing the external area as well as the efficiency of the metal and amorphous carbon removal process of the loosened bundles. The total pore volume also increases upon purification. Both figure 6 and table 1 reveal the presence of micropores. The mesopores, obtained by subtracting the micropore volume from the total, constitute the major fraction of the pores. There are a significant number of pores of diameter $>30 \mathrm{~nm}$ in the raw sample, yielding an average pore size $7.4 \mathrm{~nm}$. The purification process results in pores of much smaller size (see figure 6) pushing the average pore size down to 3.9 $\mathrm{nm}$. 
TABLE 1: KEY NANOSTRUCTURAL PROPERTIES OF RAW, DEBUNDLED AND PURIFIED SWCNT'S

\begin{tabular}{|l|l|l|l|}
\hline & Raw & Debundled & Purified \\
HiPco & HiPco & HiPco \\
\hline $\begin{array}{l}\text { BET (surface } \\
\text { area) (m/g) }\end{array}$ & 570 & 970 & 1580 \\
\hline $\begin{array}{l}\text { INTERNAL } \\
\text { AREA (m²) }\end{array}$ & 195 & 195 & 680 \\
\hline $\begin{array}{l}\text { TOTAL } \\
\text { PORE } \\
\text { VOLUME } \\
\text { (ml/g) }\end{array}$ & 1.06 & 1.26 & 1.55 \\
\hline $\begin{array}{l}\text { MICRO- } \\
\text { PORE } \\
\text { VOLUME(mI/ } \\
\text { g) }\end{array}$ & 0.08 & 0.19 & 0.28 \\
\hline $\begin{array}{l}\text { IRON } \\
\text { CONTENT } \\
\text { (\%) }\end{array}$ & $22 \%$ & $0.4 \%$ \\
\hline
\end{tabular}

\section{RHODIUM IMPREGNATION}

Luo et al [10] generated carbon nanotubes using a $\mathrm{CO}$ disproportionation reaction but with $\mathrm{Ni}-\mathrm{La}_{2} \mathrm{O}_{3}$ as catalyst. He successfully impregnated rhodium after the CNT's were treated with $1 \mathrm{M} \mathrm{HNO}_{3}$. This procedure does specify time or period of $\mathrm{HNO}_{3}$ treatment. Our efforts at impregnating DMF-DE/HCl treated SWCNT did not provide successful impregnation. Keller [11] has obtained excellent rhodium impregnation with fish nanofibers. However, this work shows that a vital prerequisite for successful impregnation is the surface oxidation with $\mathrm{HNO}_{3} / \mathrm{H}_{2} \mathrm{SO}_{4}$. This surface oxidation is necessary to ensure good interaction between aqueous catalyst precursor solutions and the CNF's. We are in the process of modifying the pretreatment and surface oxidation to ensure good rhodium impregnation.
There are also significant differences between the calcination temperatures (tc) and reduction temperatures (tr) of the rhodium impregnated carbon nanofibers and nanotubes. Keller obtained rhodium particles with diameter of $1.1 \mathrm{~nm}$ at tc $150^{\circ} \mathrm{C}$ and $\operatorname{tr} 140^{\circ} \mathrm{C}$. Increasing the tc or tr to $250^{\circ} \mathrm{C}$ resulted in bigger diameter rhodium particles $(D=1.7 \mathrm{~nm})$.

On the other hand, Luo [10] used tc of $500^{\circ} \mathrm{C}$ and tr of $300^{\circ} \mathrm{C}$. In our early study with a tc of $500^{\circ} \mathrm{C}$, it appeared that most of SWCNT's had disintegrated. Subsequently, we lowered the tc to $300^{\circ} \mathrm{C}$. We are evaluating critically these temperature effects in optimizing our rhodium impregnation and catalyst production method.

A schematic of the rhodium particle is presented below (adapted from Keller [11])

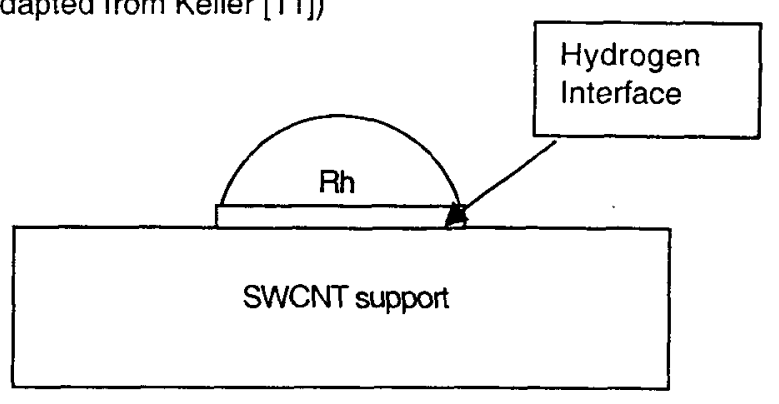

\section{HETEROGENOUS CATALYSTS AND DE-NO $x$}

At present, the application of CNT's in heterogeneous catalysis is still in its infancy. Selective hydrogenation of cinnamaldehyde to cinnamyl alcohol on CNT's supported ruthenium and platinum catalysts have been reported in the literature[12] Similar selectivity has been reported in the hydrogenation of $\mathrm{CO}$ and 2-cyclohexenone[13]. CNT's and CNT supported rhodium have also been investigated for NO dissociation[10]. Previous studies have also reported selective uptake of $\mathrm{NO}$ and $\mathrm{O}_{2}$ over CO[15]. In catalysis with noble metals, the oxidation state of the noble metal in a catalyst has direct influence on the catalytic performance.

It is generally believed that the decomposition of NO follows the redox mechanism:

$$
\begin{aligned}
& \mathrm{M}^{\mathrm{n}+}=\mathrm{M}^{(\mathrm{n}+1)+}+\mathrm{e} \\
& \mathrm{NO}+\mathrm{e}=\mathrm{NO}^{-}
\end{aligned}
$$

Where $M$ is a metal and $n=0,1$ or 2 . Subsequently, the adsorbed $\mathrm{NO}^{\circ}$ can decompose to $\mathrm{N}_{2}$ and $\mathrm{O}_{2}$ via intermediates such as $\mathrm{N}_{2} \mathrm{O}_{2}{ }^{2 \cdot}$ and $\mathrm{NO}_{2}$. In the reaction, $\mathrm{M}^{n+}$ serves as the active site. If the recovery of $\mathrm{M}^{\text {nt }}$ from $\mathrm{M}^{(n+1)+}$ is not timely, $\mathrm{M}^{(n+1)+}$ would accumulate. As a result, the conversion of NO is hindered. The strong interactions between metal and carbon support have been extensively studied. Braun et al. [14] pointed out that $\eta 2$ type metal-carbon bonds could be formed in 
fullerene-based ruthenium catalysts. The presence of fullerenes should therefore cause an interaction between the metal and the substrate, one that is different from the interaction of conventional carbon materials with the metal particles. Similar viewpoints have also been made on CNT materials[15].

For instance, in NO decomposition on Pd, it has been observed that the active center for no decomposition is metallic $\mathrm{Pd}^{0}$ rather than $\mathrm{Pd}^{2+}$. With CNTs supported rhodium, it has been revealed through transmission electron microscopy (TEM), temperature programmed reduction (TPR), and $x$-ray photoelectron spectroscopy (XPS) studies that the presence of CNTs is favorable for the retention of metallic rhodium and the catalytic activity of rhodium is enhanced as a result[10]. In the study, the surface area of the CNTs used were approximately 180 $\mathrm{m}^{2} / \mathrm{g}$ before impregnation and about $140 \mathrm{~m}^{2} / \mathrm{g}$ after impregnation. Purification steps to increase the surface area would significantly enhance the catalytic activity of the CNT supported catalysts.

\section{CONCLUSION}

The two-step purification method has yielded SWCNT's with a very high surface area of $1580 \mathrm{~m}^{2} / \mathrm{g}$ and low impurity level $<0.4 \%$, which are both the highest that we have seen reported in the literature. However, there are still some variations, which we are working on to ensure good reproducibility in the different batches of purified SWCNT to be produced.

We recognize the limitations to successful rhodium impregnation and we are proceeding with efforts at optimizing rhodium impregnation conditions to ensure the best quality of the rhodium in SWCNT's. This will be followed by catalyst characterization and toxic gas conversion test.

\section{ACKNOWLEDGMENTS}

Christina Binder for TGA work; NASA Ames Research Center for DDF funding; Professor Smalley for providing samples of HiPCO. This study is now progressing under a 3-year NASA-NRA funding at NASA Ames Research Center

\section{REFERENCES}

1. Y.F. Yin, T. Mays and B. McEnaney (1999) Langmuir 15:8714

2. L.W. Chiang, B.E. Brinson, A.Y. Huang, P.A. Willis, M.J. Bronikowski, J.L. Margrave, R.E. Smalley and R.H. Hauge (2001) J. Phy. Chem. B 1058297

3. W. Du, L. Wilson, J. Ripmeester, R. Dutrsac, B. Simard and S. Denommee (2002) Nanoletters 2: 343

4. M. Yudasaka, H. Kataura, T. Ichihashi, L.C. Qin, S. Kar ans S. ljima (2001) Nanoletters 1: 487

5. P. Nikolaev, M.J. Bronikowski, R.K. Bradley, F. Rohmund, D.T. Colbert, K.A. Smith, and R.E. Smalley (1999) Chem. Phys. Letts. 333:91
6. L. Delzeit, B. Chen, A. Cassell, R. Steven, C. Nguyen and M. Meyappan (2001) Chem. Phys. Lett. 348: 368 -

7. P.A. Webb and C. Orr (1997) Analytical Methods in Fine Particle Technology. Micromeritics

8. A. Jorio, M.S. Dresselhaus, M. Souza, M.S.S. Dantas, M.A. Pimenta, A.M. Rao, R. Saito, and C. Liu. (2000) Phys. Rev. Lett. 85:2617

9. C.M. Yang, K. Kaneko, M. Yudasaka and S. ljima (2002) Nanoletters 2:385

10. J. Z. Luo, L.Z. Gao, Y.L. Leung and C.T. Au (2000) Catalyst Lett $66: 91$

11. D. E. Keller (2002) Ph.D. thesis, University of Utrecht, Netherlands

12. G.U. Sumanasekera, C.K.W. Adu, S. Fang and P.C. Eklund (2000) Phy. Rev. Letts. 85: 1096-1099

13. E. Ronzon and G. Del. Angel (1999) J. Molecular Catalysis A: Chemical 148:105

14. Braun Th, M. Wohlers, T. Belz, G. Nowizke, G. Wortmann, Y. Uchida, N. Pfander and R. Schogel (2000) Catlyst. Lett. 43:175

15. M. Rasinkangas, T.T. Pakkanen and T.A. Pakkanen (1994) J. Organomet. Chem. 476:C6

\section{CONTACT}

Martin Cinke, Eloret Corporation, NASA-Ames Research Center, MS 229-1, Moffett Field, CA 94035-1000

E-mail: mcinke@mail.arc.nasa.gov

\section{DEFINITIONS, ACRONYMS, ABBREVIATIONS}

HiPco High Pressure CO disproportionation reaction

SWCNT Single Walled Carbon NanoTube

CNT Carbon NanoTube

CNF Carbon nanofibers

BET Brauner-Emmett Teller Surface Area

DMF Dimethyl formamide

EDA Ethylene Diamine HRTEM High Resolution Transmission Electron
Microscopy

TGA Thermogravimetric analysis

TEM Transmission Electron Microscopy

TPR Temperature Programmed Reduction

XPS X-ray photoelectron spectroscopy 